\title{
Evaluation of the Volume Stability and Resource Benefit of Basic Oxygen Furnace Slag and Its Asphalt Mixture Based on Field Application
}

\author{
Yuechao Zhao, Jiangkai Song, Jun Xie, Fusong Wang ${ }^{(D)}$, Meizhu Chen, and Shaopeng Wu \\ State Key Laboratory of Silicate Materials for Architectures, Wuhan University of Technology, Wuhan 430070, China \\ Correspondence should be addressed to Shaopeng Wu; wusp@whut.edu.cn
}

Received 3 December 2020; Accepted 3 December 2021; Published 23 December 2021

Academic Editor: Loke Foong

Copyright (c) 2021 Yuechao Zhao et al. This is an open access article distributed under the Creative Commons Attribution License, which permits unrestricted use, distribution, and reproduction in any medium, provided the original work is properly cited.

\begin{abstract}
Applying basic oxygen furnace (BOF) slag as aggregate in asphalt mixture is continuously investigated due to the increasing shortage of natural aggregate in recent years. However, the negative effect of BOF's expansion in water greatly limits its further application in pavement construction. To address this problem, this paper studied the volume stability of BOF, and its asphalt mixture relied on actual engineering. The asphalt mixtures contained BOF aggregate was designed by the Marshall method with three different gradation types (AC-16, AC-20, and ATB-25). Besides, both laboratory samples and the core samples from field drilling were investigated in volume expansion rate after curing in a water bath. The economic and resource benefits of BOF replacement of natural aggregates were also analyzed. The results showed that the free calcium oxide content of BOF slag is positively related to the particle sizes. Nevertheless, the expansion rates of both the BOF aggregate and its asphalt mixture were less than $1 \%$, which meant the BOF aggregate applied to the asphalt mixture meets the practical engineering requirements. The maximum allowable free calcium oxide content for large-grain size of steel slag is the smallest; it is also recommended that the expansibility of large-grain steel slag should be the first concern in the application. The resource assessment indicated that the use of steel slag for the construction of a trial section of one kilometer of single lane can save 967 tons of natural aggregates. The economic evaluation showed that the use of steel slag instead of natural aggregates for surface course construction could reduce the investment by $16.87 \%$. The experimental methods and conclusions mentioned in this article provide stable references to enhance the development of sustainable pavement by recycling metallurgical slag in highway construction.
\end{abstract}

\section{Introduction}

Asphalt pavement has been widely used in high-grade highways because of its unique advantages, such as comfortable driving, low noise, and short construction period [1-4]. Asphalt binder, aggregate, and mineral filler are the three major elements of asphalt concrete. Aggregate, which accounts for more than $90 \%$ of the total volume of asphalt concrete, as the primary skeleton plays a key role in resisting vehicle load $[5,6]$. The quality of aggregate has remarkable impacts on road performance and life period $[7,8]$. In recent decades, superior natural aggregate for high-grade highway construction such as limestone and basalt have become a scarce resource due to excessive extraction [9]. Regulations restricting sand and gravel mining have also been promulgated throughout China. Natural aggregates are expensive and difficult to obtain. However, as the world's largest developing country, China's investment of resources in large-scale infrastructure construction is inevitable. Because of the practical demands of road network improvements, there is an urgent need to find succedaneum to relieve the extreme shortage of natural stones for road construction [10].

Steel slag is a typical by-product of steel smelting process. Every 100 tons of crude steel produced will bring $10-15$ tons of steel slag [11-14]. The large accumulation of steel slag not only wastes substantial land resources but also brings potential pollution and adverse effects on groundwater, plants, and air [15-18]. Basic oxygen furnace slag (BOF) is a widespread type of steel slag, which is workable in antiskid 
and abrasion resistance due to predominant textures and abundant angularity [19-21]. Therefore, applying BOF slag as raw materials for roads construction seems to be an effective way to save precious natural aggregates [22-24]. Meanwhile, the environmental pressure caused by the accumulation of steel slag may be alleviated [22].

Pasetto and Baldo [25, 26] evaluated high performance base course and road base asphalt concrete with electric arc furnace steel slags. The experimental results demonstrated that steel slag can enhance the performances of asphalt mixture such as high-temperature deformation resistance, abrasion, and skid resistance. Masad et al. [27] discovered that the BOF slag has stronger bonding strength with asphalt binder than natural stones. Tao et al. [28] grind BOF slag into powder instead of limestone filler. The result indicated that asphalt mixture with BOF slag powder as filler possesses excellent water damage resistance [29, 30]. Meanwhile, Wan et al. [31, 32] observed that steel slag contains effective components for induction heating which can be used to preparation deicing pavement. It also proved that the $\mathrm{Fe}_{3} \mathrm{O}_{4}$ plays the dominant part to steel slag induction heating when their sizes are smaller than $75 \mu \mathrm{m}$. Cui et al. [33] recycled steel slag as aggregate in chip seals. The results found that the self-bonded function of chip seal can be enhanced by steel slag. Besides, a remarkable economic efficiency of ship seal with deicing and self-bonded functions can be observed. Hainin et al. [14] summarized the engineering properties of steel slag and its application advantages for road construction and proposed that the geotechnical characteristics of steel slag needs some attention, because the shear strength parameters and the compaction characteristics have not been studied properly. Pathak et al. [34] evaluated the benefit of open gradation friction layer of basic oxygen furnace steel slag aggregate in the hilly region of India. Results showed that steel slag used as coarse aggregate improved the frictional resistance of OGFC mixes.

However, the great mass of these studies was carried out in the laboratory. Few roads have been built with BOF slag as substitutes for natural aggregates on a large scale [1]. The reason is mainly that part of the quicklime used in the steelmaking process will become free quicklime if it is not fully combined. If such BOF is piled in large pieces without being crushed in advance, it will react to form calcium hydroxide when it meets water, which results in volume expansion about twice [35-37]. The expansion force caused be steel slag hydration may shorten the service life of roads and even bring hidden dangers to driving safety [38, 39]. The volume instability has become the primary obstacle to its application on the road. Besides, the BOF produced in different regions will also vary greatly [40]. Only if the accumulation time is long enough can steel slag with free calcium oxide content within a safe range be successfully applied to pavement engineering. Therefore, strict material selection and detection are the most critical step for the successful application of BOF [35].

The author's research team used Baotou Iron and Steel Group's abundant BOF resources to construct dozens of kilometers of steel slag asphalt trial pavement in Inner Mongolia during the past three years relying on Major Science and Technology Projects of Inner Mongolia Autonomous Region. The free calcium oxide content determination was carried out in concert to strictly control the degree of deposition of the applied steel slag. Besides, the expansion rates of the BOF slag and its asphalt concrete were measured. The economy and resources benefit brought by BOF slag instead of natural aggregate was also discussed. The main purpose of this research is to rely on actual engineering to provide stable references to enhance the development of sustainable pavement by recycling metallurgical slag in highway construction.

\section{Experimental Design}

2.1. Materials. Virgin asphalt graded 90 (penetration grade) and SBS-modified asphalt (Changhe Chemical Co. Ltd., Heilongjiang, China) were used as binders in this study. Limestone filler (Chengxin Aggregates, Inner Mongolia, China) with a hydrophilic coefficient of 0.83 was employed as filler. The basic properties of used asphalt binders are shown in Table 1.

Basic oxygen furnace (BOF) slag provided by Baotou Iron and Steel Group, Inner Mongolia, China, was used as aggregate in this study. BOF slag had been deposited about seven years before the application. The physical properties of BOF slag were investigated, including apparent specific gravity, water absorption, flakiness content, Los Angeles abrasion, and crush values. Three control experiments were done for each grade of aggregate. The experiment results are listed in Table 2.

\subsection{Experimental Methods}

2.2.1. Gradation Design. Baotou-Maoming Expressway, which is numbered G65 in China's National Expressway Network, was designed with six pavement structure layers. The steel slag asphalt concrete trial pavement is planned to be laid on the upper, middle, and lower surface course, respectively. Three different gradation types, namely, AC-16, AC-20, and ATB-25, were designed, respectively, according to the Marshall design method. Sieve pass rates of steel slag asphalt concrete with different gradations are shown in Table 3.

\subsubsection{Free Calcium Oxide Content Tests.} Glycerin-ethanol titration was used in this paper to determine the content of free calcium oxide in BOF slag. The experimental process and device are shown in Figure 1. The residual calcium oxide in the steelmaking process exists in the steel slag in the form of a free state. Calcium glycerin can be formed when it is azeotropic with the ethanol-glycerin solution. The reaction can be accelerated by adding the proper amount of strontium nitrate and alumina mixture into glycerol-anhydrous ethanol solution as a catalyst. The chemical reaction involved is shown in $\left(R_{1}\right)$. Calcium glycerin is weakly alkaline, which can make phenolphthalein indicator red. The reaction equation is shown in $\left(R_{3}\right)$. The mixture is titrated with a weakly acidic benzoic acid solution until the red color disappears completely. The corresponding chemical reaction is shown in $\left(R_{2}\right)$. The content of free 
TABLE 1: Basic properties of binders.

\begin{tabular}{lccrr}
\hline Materials & Properties & Values & Specification & Standard \\
\hline & Penetration $\left(25^{\circ} \mathrm{C}, 0.1 \mathrm{~mm}\right)$ & 92 & $80-100$ & T0604-2011 \\
Matrix asphalt & Ductility $\left(15^{\circ} \mathrm{C}, \mathrm{cm}\right)$ & $>100$ & 100 & T0605-2011 \\
& Softening point $\left({ }^{\circ} \mathrm{C}\right)$ & 46 & 245 & T0606-2011 \\
& Density $\left(\mathrm{g} / \mathrm{cm}^{3}\right)$ & 1.025 & - & T0603-2011 \\
\hline & Penetration $(25,0.1 \mathrm{~mm})$ & 69 & $60-80$ & T0604-2011 \\
SBS- (I-C-) modified asphalt & Ductility $\left(5^{\circ} \mathrm{C}, \mathrm{cm}\right)$ & 68.5 & 230 & T0605-2011 \\
& Softening point $\left({ }^{\circ} \mathrm{C}\right)$ & 59 & - & T0606-2011 \\
& Density $\left(\mathrm{g} / \mathrm{cm}^{3}\right)$ & 1.026 & T0603-2011 \\
\hline
\end{tabular}

TABLE 2: Fundamental properties of BOF slag.

\begin{tabular}{lcccc}
\hline Aggregate size $(\mathrm{mm})$ & Apparent specific gravity & Water absorption (\%) & $\begin{array}{c}\text { Flakiness } \\
\text { content (\%) }\end{array}$ & Los Angeles abrasion (\%) \\
\hline $0-2.36$ & 3.556 & 1.81 & - & - \\
$2.36-5.5$ & 3.774 & 1.80 & - & 8.3 \\
$5.5-11$ & 3.789 & 0.90 & 9.8 & 9.4 \\
$11-18$ & 3.755 & 0.70 & 7.3 & 13.2 \\
$18-22$ & 3.766 & 0.60 & 6.8 & 12.8 \\
$22-27$ & 3.752 & 0.50 & $\leq 12$ & $\leq 28$ \\
Criteria in China & $\geq 2.9$ & $\leq 3.0$ & & \\
\hline
\end{tabular}

TABLE 3: Gradation composition of steel slag asphalt concrete.

\begin{tabular}{lccc}
\hline \multirow{2}{*}{ Sieve size $(\mathrm{mm})$} & \multicolumn{3}{c}{ Passing ratio (\%) } \\
\hline 31.5 & AC-16 & AC-20 & ATB-25 \\
26.5 & 100.0 & 100.0 & 100.0 \\
19 & 100.0 & 100.0 & 99.6 \\
16 & 100.0 & 96.8 & 75.2 \\
13.2 & 93.0 & 84.8 & 62.9 \\
9.5 & 85.8 & 75.7 & 54.7 \\
4.75 & 71.7 & 62.4 & 45.9 \\
2.36 & 47.7 & 40.4 & 36.1 \\
1.18 & 30.1 & 25.1 & 24.9 \\
0.6 & 23.2 & 19.5 & 19.4 \\
0.3 & 16.6 & 14.1 & 14.1 \\
0.15 & 11.3 & 9.8 & 9.8 \\
0.075 & 8.6 & 7.5 & 7.5 \\
\hline
\end{tabular}

calcium oxide in steel slag can be calculated according to the consumption of benzoic acid solution. Three replicates for each particle size were conducted.

2.2.3. Hydration Treatment of Steel Slag. The hydration treatment can effectively eliminate the free calcium oxide content of BOF slag due to its sensitivity to moisture. The free calcium oxide content in steel slag before and after hydration treatment was quantified in this study. The surface of BOF slag was kept wet but not immersed in water in order to get hydration product accumulated on the surface of BOF slag [1]. The above process was carried out twice a day. The content of free calcium oxide in the BOF slag was measured after 3 days.

2.2.4. Optimal Moisture Content Tests. The heavy compaction test was used to determine the optimal moisture content of BOF slag in this study. The weight of the hammer is $4.5 \mathrm{~kg}$, and the drop height is $45 \mathrm{~cm}$. The entire aggregates were filled in three layers, and each layer was compacted 98 times. The dry density calculation method is (1). Draw a curve with dry density as the ordinate and water content as the abscissa. The abscissa corresponding to the peak point on the curve is the optimal water content of the sample:

$$
\rho_{d}=\frac{\rho_{w}}{(1+w)}
$$

where $\rho_{d}$ is the dry density $\left(\mathrm{g} / \mathrm{cm}^{3}\right), \rho_{w}$ is the wet density $(\mathrm{g} /$ $\left.\mathrm{cm}^{3}\right)$, and $w$ is the water content (\%).

2.2.5. Expansion Tests of Steel Slag. The heavy compaction tests were conducted using actual asphalt mixture grades according to the compaction test method for base materials. The weight of the hammer is $4.5 \mathrm{~kg}$, and the drop height is $45 \mathrm{~cm}$. The entire aggregates were filled in three layers, and each layer was compacted 98 times to determine the optimum moisture content and maximum dry density.

Three heavy compaction specimens of $150 \mathrm{~mm}$ diameter with a total weight of about $7 \mathrm{~kg}$ were prepared according to the actual gradation of the project. A certain amount of water was added to the above mixture according to the optimal moisture content $( \pm 1 \%)$. Finally, the fully mixed mixtures were placed in a closed container for 24 hours for compaction test.

Four semicircular carrier plates weighing $1.25 \mathrm{~kg}$ each pressed on the porous plates. A dial indicator for measuring the amount of expansion on which the dial indicator shall be accurately aligned with the central contact and maintained upright was used. Finally, the device was moved to a thermostatic water bath with the temperature set at $80^{\circ} \mathrm{C}$. The system was maintained at the desired temperature for 6 hours, and then it can cool naturally. The dial indicator was read before heating the next day. The device should be 


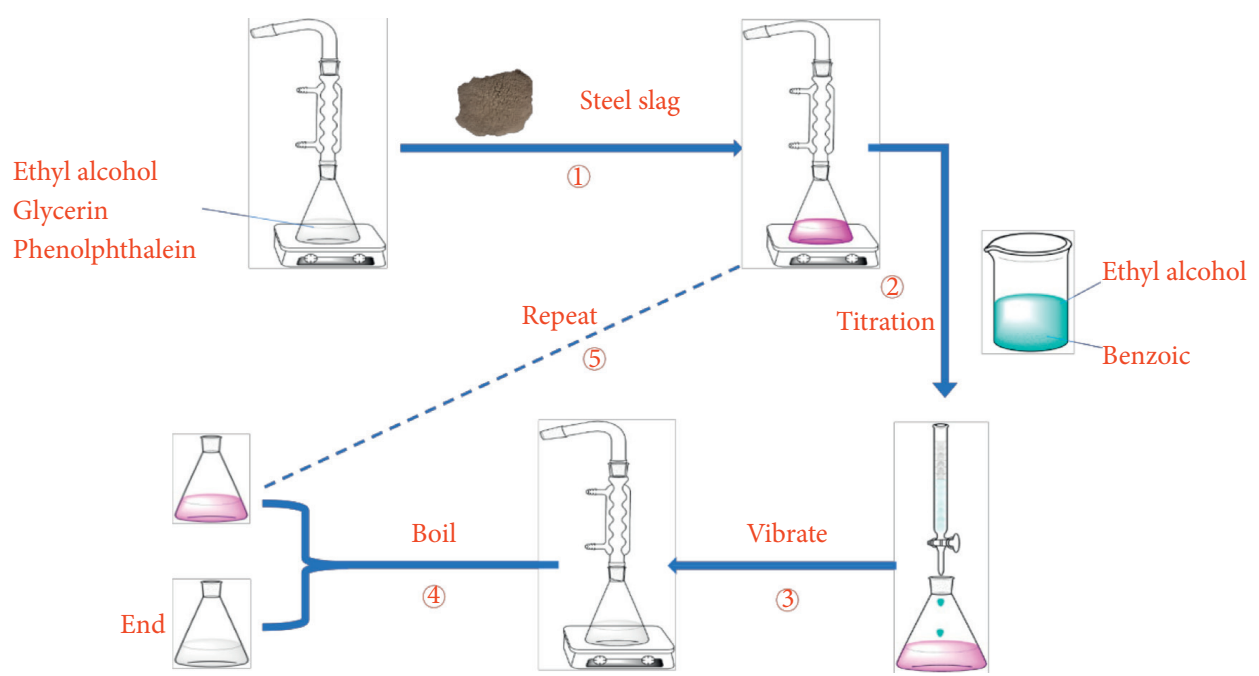

Figure 1: Schematic of the determination process of free calcium oxide in steel slag.

heated and cooled once a day for a total of 10 days. Three replicates for each sample were conducted.

\subsubsection{Expansion Tests of Asphalt Mixture with Steel Slag.} The expansion tests for standard Marshall specimens and core samples that were drilled in the field can reflect the possible damage of pavement in the actual service process. According to the actual mix ratio of steel slag asphalt mixture, three standard Marshall specimens were prepared in the laboratory, and two pavement core samples were drilled by asphalt mixture core-drilling machine in the asphalt pavement construction site for the test of asphalt concrete expansion. The caliper was used to carefully measure 3 sections in the diameter direction of the specimen and 4 sections in the height direction. The volume $V_{1}$ of specimen was calculated. The specimens were then placed in a $60^{\circ} \mathrm{C}$ constant temperature water bath for $72 \mathrm{~h}$. The volume $V_{2}$ of the specimens was determined immediately after the curing process at the same site. The expansion rate of steel slag asphalt concert is calculated according to

$$
C=\frac{V_{2}-V_{1}}{V_{1}} \times 100,
$$

where $C$ is the expansion rate of steel slag asphalt concert, (\%), $V_{1}$ is the volume before immersion, $\left(\mathrm{cm}^{3}\right)$, and $V_{2}$ is the volume after immersion $\left(\mathrm{cm}^{3}\right)$.

2.2.7. Calculation of Raw Materials and Costs. The calculation method of resource benefit and economic benefit brought by steel slag substituting natural aggregate is formulated in the following equations:

$$
\begin{aligned}
M & =v * \rho_{f}, \\
M_{B} & =M * a, \\
M_{A} & =M *(1-a),
\end{aligned}
$$

$$
M_{F}=m_{a} * f_{i},
$$

where $M$ is the quality of the asphalt concrete, $(\mathrm{t}) ; V$ is the construction scale, $\left(\mathrm{m}^{3}\right) ; \rho_{f}$ is the bulk density of asphalt concrete, $\left(\mathrm{g} / \mathrm{cm}^{3}\right) ; M_{B}$ is the quality of asphalt binder, $(\mathrm{t}) ; a$ is the amount of asphalt, (\%); $M_{A}$ is the quality of aggregate, (t); $M_{F}$ is the quality of filler; and $f_{i}$ is the mass fraction of filler in aggregate, (\%).

\section{Results and Discussion}

3.1. Free Calcium Oxide Content of Steel Slag. The free calcium oxide content of steel slag with different grain sizes is shown in Figure 2. It can be seen from the figure that the content of free calcium oxide increases with the increase of particle size. The results indicate that the content of free calcium oxide in steel slag is closely related to the size of steel slag. However, the maximum content is only $1.2958 \%$, which is far lower than the industry standard of $3 \%$. The BOF slag used in this study has been stockpiled for at least 7 years. Steel slag has already reacted in advance when they encounter moisture in the air during the process of accumulation and aging. Consequently, the overall free calcium oxide in BOF slag presents a lower content. Besides, the granules with small particle sizes have a larger specific surface area, which accelerates the digestion rate of free calcium oxide. That is because they can be more fully exposed to moisture than large pieces of steel slag. For steel slag with larger particles, a large amount of free calcium oxide exists inside the particles. It is difficult for the moisture to penetrate and react with them in a short time. Therefore, there is a strong correlation between the content of free calcium oxide and the particle size of steel slag. It is suggested that the newly produced steel slag should be broken into granules as soon as possible to accelerate the reaction of free calcium oxide. Overall, the steel slag used in this research fully meets the specification requirements only from the perspective of free calcium oxide content. 


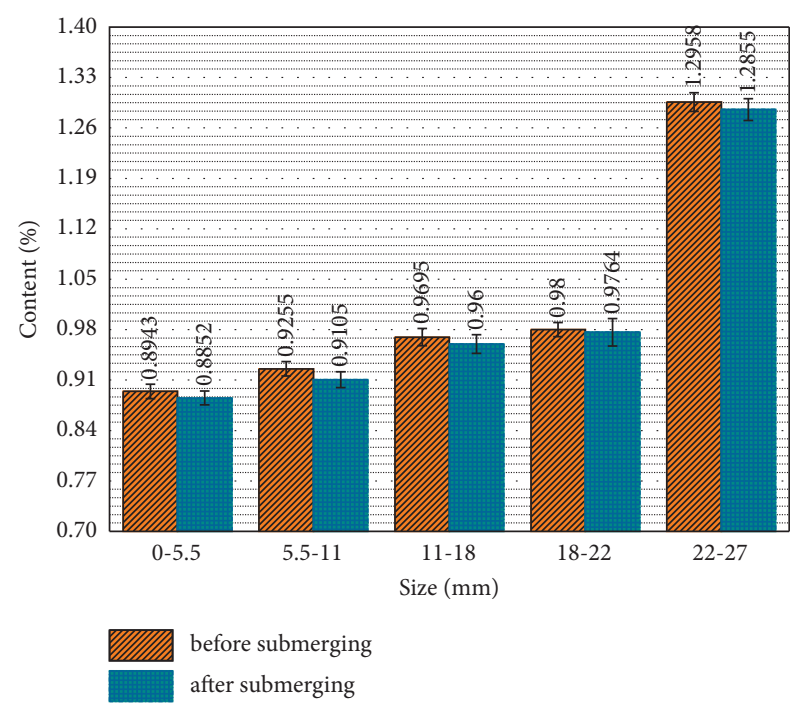

FIGURE 2: Content of free calcium oxide in steel slag with different particle sizes.

The content of free calcium oxide in the steel slag after three days of water treatment is also shown in Figure 2. It can be summarized in Figure 2 that the free calcium oxide content of samples of various particle sizes decreased in different ranges after being sprayed for three days. The free calcium oxide content of steel slag with different particle sizes decreased by $0.0091 \%, 0.015 \%, 0.0095 \%, 0.0036 \%$, and $0.0103 \%$ respectively. It can be inferred that the free calcium oxide in the steel slag is sensitive to water vapor. Therefore, fresh steel slag can be manually sprayed with water vapor during crushing, stacking, and transportation to predigest the calcium oxide to maximize its volumetric stability.

Wang et al. [35] proposed the maximum allowable free lime content in consideration of free volume, external pressure, and precipitated lime. When the measured value of free lime is less than $4 \%$, the maximum allowed free lime content can be calculated by

$$
F_{\text {all }}<2.0 \%+\frac{0.075\left(\gamma_{s}-\gamma_{0}\right)}{0.38 \gamma_{s}^{2}}
$$

where $F_{\text {all }}$ is the maximum free lime content for given steel slag, $\gamma_{s}$ is the specific gravity of steel slag $\left(\mathrm{g} / \mathrm{cm}^{3}\right)$, and $\gamma_{0}$ is the bulk density of steel slag $\left(\mathrm{g} / \mathrm{cm}^{3}\right)$.

It states if the free calcium oxide content of steel slag is not more than the righthand term, the steel slag will not expand macroscopically. The expansion caused by free calcium oxide can be regarded as being absorbed by the cavities of the steel slag itself under the action of external force. The allowable free lime content for the steel slag used in this study can be obtained according to the above equation. The relevant parameters and calculation results are listed in Table 4.

It can be seen from Table 4 that the maximum allowable free lime content decreases as the particle size increases. For example, steel slag with a particle size of less than $5.5 \mathrm{~mm}$ can be considered that the expansion will be absorbed by its pores when the content of free calcium oxide is not more
TABLE 4: Allowable free lime content for steel slag.

\begin{tabular}{lccc}
\hline Size $(\mathrm{mm})$ & $\gamma_{s}(\mathrm{~g} / \mathrm{cm})$ & $\gamma_{0}(\mathrm{~g} / \mathrm{cm})$ & $F_{\text {all }}(\%)$ \\
\hline $0-5.5$ & 3.774 & 3.533 & 2.334 \\
$5.5-11$ & 3.789 & 3.673 & 2.159 \\
$11-18$ & 3.755 & 3.667 & 2.123 \\
$18-22$ & 3.766 & 3.692 & 2.103 \\
$22-27$ & 3.752 & 3.688 & 2.090 \\
\hline
\end{tabular}

than $2.334 \%$. However, If the expansion of steel slag with a particle size of $22 \mathrm{~mm}$ or more is to be ignored, the maximum free calcium oxide content allowed is reduced to $2.090 \%$. Furthermore, it is concluded in the previous chapter that the free calcium oxide content of steel slag is proportional to its particle size. Consequently, it is recommended that attention should be paid to whether large-diameter particles meet the requirements when steel slag is used as aggregate.

\subsection{Volume Stability Evaluation}

3.2.1. Volume Stability of Steel Slag. The heavy compaction tests on BOF slag were carried out in accordance with the compaction test method for base materials. The BOF slag mixture needs to be activated at the optimal moisture content before the experiment. The relationship between the maximum dry density and the optimal water content of the sample used in the heavy compaction experiment is shown in Figure 3. When the water content of the system increases from $1 \%$ to $2 \%$, the dry density of the sample increases from $2.7423 \mathrm{~g} / \mathrm{cm}^{3}$ to $2.7647 \mathrm{~g} / \mathrm{cm}^{3}$. And the density is almost close to the peak value. However, the dry density of the sample began to decrease continuously when the water content of the system was continued to increase. Therefore, $2 \%$ of the water content was taken as the optimal water content. And the sample was processed on this basis.

The expansion of the experimental mixture prepared according to the actual gradation of the project is shown in Figure 4 . The three steel slag mixtures with different grades all showed obvious expansion during the first 6 days of curing. As shown in Figure 4, the ATB-25 graded mixture had the largest expansion height in the compaction barrel, which is $0.661 \mathrm{~mm}$. The maximum expansion height of the AC-16 graded mixture was only $0.22 \mathrm{~mm}$ after 10 days in the water bath. The expansion height of the AC-20 graded mixture was $0.582 \mathrm{~mm}$, which is somewhere in between. The results of the aggregate expansion were fit to the result of free calcium oxide content measured above. The mixture system with more large particles also contains more free calcium oxide. Consequently, there is a greater expansion phenomenon in comparison. Nevertheless, the expansion of the three gradations meets the specification requirements.

Yunpeng et al. [41]. studied the water swelling rate of two steel slags from different origins in the laboratory and one group of steel slag produced in the same place as the steel slag used in this study. Liu et al. found that the initial expansion rate of BOF slag produced in Inner Mongolia was relatively small and showed a small and steady increase trend with the increase of curing time. The expansion rate is only 


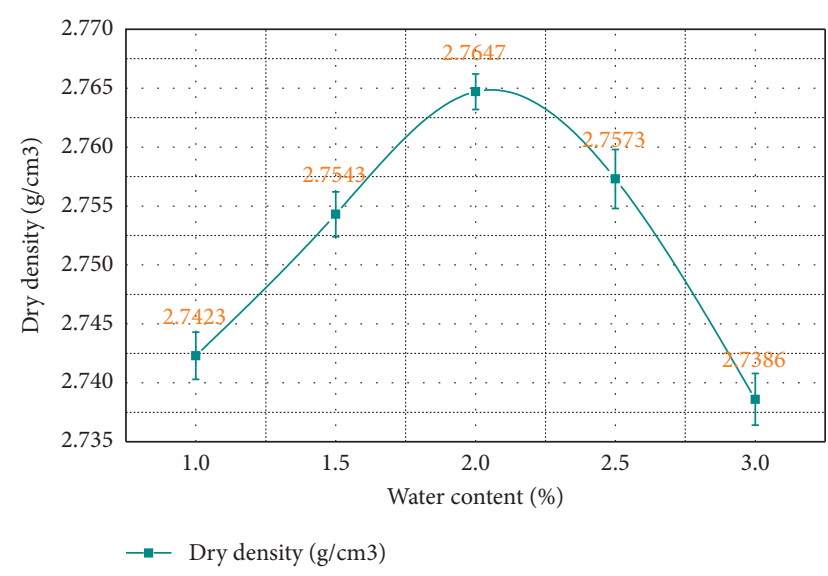

FIGURE 3: The relation between maximum dry density and water content.

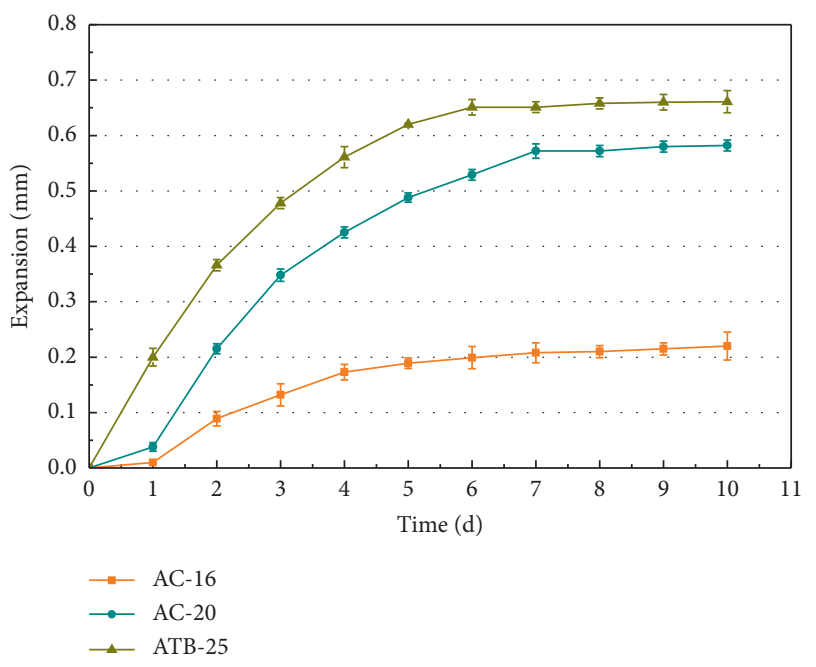

FIGURE 4: Expansion of steel slag mixture with different gradations.

$0.45 \%$ after 10 days of water bath curing. It also can be seen that the experimental results obtained from the field are consistent with the laboratory.

In another study, Chen et al. studied the effect of hydration and silicone resin on BOF slag [1]. The expansion time and ratio of BOF slag after fully hydration and silicone resin treatment are reduced. The results illustrated that hydration and silicone resin both can restrain the slag's volume expansion. However, it is difficult to apply silicone resin to treat steel slag on a large scale in construction sites. Therefore, this study only explored the impact of water treatment on steel slag in the previous chapter. The experimental results also show that the advanced water treatment can make the free calcium oxide in the steel slag react in advance to ensure its volume stability.

Zhang reported that the expansion rate of $10 \mathrm{~d}$ immersion is very effective for the production quality control of the stability of steel slag for road construction. It is found that the expansion of steel slag specimens less than $2 \%$ within 10 days is not significant after 10 days. However, if the steel slag exceeds $2 \%$ within 10 days, the expansion of most samples will not converge in the later period [42]. The expansion curves obtained in this study are consistent with the conclusion.

\subsubsection{Volume Stability of Steel Slag Asphalt Mixtures.} There is a huge distinction between laboratory experiments and industrial production due to the large disparity of material handling capacity. The results from the laboratory cannot fully reflect the real application situation. To reflect the actual conditions of the pavement as realistic and comprehensively as possible, the standard Marshall specimens used in the asphalt mixture expansion experiment were compacted and molded from the mixture produced by the mixing station. Besides, a core-drilling sampling machine was used to directly drill cylindrical specimens from the pavement as another source of samples after the pavement was compacted and solidified for 48 hours. Meanwhile, the adhesion between aggregates during water soaking may be impaired by water immersion, resulting in a degree of expansion that is not caused by free calcium oxide. Consequently, Marshall specimens with basalt as controls were also subjected to the same expansion tests.

The expansion ratios of the asphalt mixture under three different gradations are shown in Figure 5. It can be seen from Figure 5 that both the asphalt mixture with steel slag and mixture with basalt showed slight expansion in volume after 3 days of curing in the water bath. The expansion rates of asphalt mixtures containing steel slag are higher compared with the ordinary mixture. However, the corrected expansion rates are less than $0.5 \%$ when ignoring the expansion that is not caused by lime. Steel slag would be wrapped around a layer of asphalt film during the forming process of asphalt mixtures. The excellent waterproof property of asphalt effectively prevents the junction of free calcium oxide and moisture in the steel slag. Consequently, the chance of hydration reaction between lime and water vapor is greatly reduced. Therefore, an appropriate oil-stone ratio can ensure that each aggregate is tightly wrapped by the oil film which can inhibit the expansion of the asphalt mixture with steel slag. The experimental results also show that the expansion of the ATB-25 graded mixture is more obvious than that of AC-20 and AC-16. The expansion phenomenon is more obvious in the gradation with more large-sized steel slag. In other words, the expansion experiment results of the mixture are consistent with the expansion results of the steel slag aggregate. The same conclusion was also reported by Chen et al. [1].

\subsection{Resource and Economy Analyses}

3.3.1. Resource Benefits Assessment. There are two ways to replace natural aggregate with BOF slag, namely, full replacement (100\% aggregate substituted) and partial replacement (BOF slag as coarse aggregate). The higher the proportion of steel slag in the asphalt mixture, the greater the possibility of expansion cracks in the road. Thus, steel slag is generally not used to replace natural aggregates fully in practical applications. When $\mathrm{BOF}$ slag partially replaces 


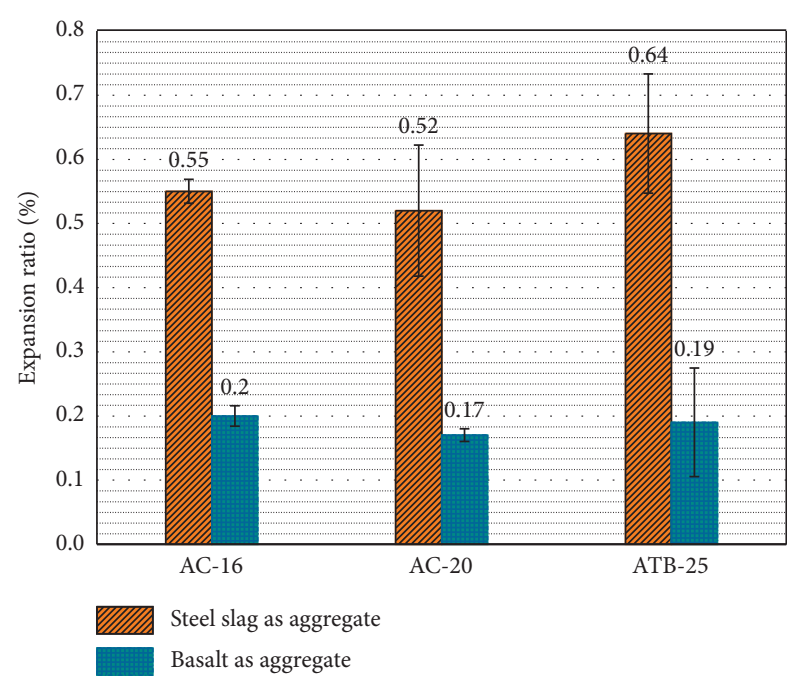

FIGURE 5: The volume expansion rate of asphalt mixture with steel slag.

natural aggregates, it is more reasonable to use only the particle size larger than $2.36 \mathrm{~mm}$ to blend into the mixture. On the one hand, the coarse aggregate of steel slag can further reduce the amount of asphalt and reduce the cost of preparation. On the other hand, the dust content on the surface of steel slag coarse aggregate is much lower than that of fine aggregate. High dust content will affect the normal operation of the machine during mixing [43]. For the completeness of the research, this study carried out field application of the above two ways of replacing natural aggregate with steel slag.

Figure 6 uses the lower surface course as an example to show the demand for various raw materials for a $10 \mathrm{~km}$ single-lane road (the width is $3.75 \mathrm{~m}$ and the thickness is $0.11 \mathrm{~m}$ ) for three different gradations. NA means that all the aggregate uses basalt; BOFA means that all the aggregate uses steel slag; BOFA (C) indicates that the coarse aggregate uses steel slag. It can be seen from Figure 6 that 7,870 tons of basalt can be saved per 10 kilometers of a single-lane road when the coarse aggregate is replaced by BOF slag. Meanwhile, 9,070 tons of waste steel slag can be disposed of. However, the amount of asphalt and filler have increased by 23 tons and 194 tons, respectively, due to the porous properties of steel slag. When natural aggregates are replaced by steel slag fully, 9,670 tons of basalt can be saved for every 10 kilometers of single-lane road, and 12,490 tons of waste steel slag can be disposed of, which is a meaningful protection method for the environment and the land. The amount of asphalt and filler increased by 40 tons and 210 tons accordingly. The number of saved materials and waste disposal of the surface source are listed in Table 5 .

Marina also pointed out in his life cycle assessment (LCA) study on steel slag that the high yield of steel slag means that slag accumulation is a thorny issue. It is an urgent need for the environment to avoid the burial of such wastes and give them value for use [44]. From Figure 6 and Table 5, it can be concluded that the asphalt mixture prepared by steel slag instead of natural

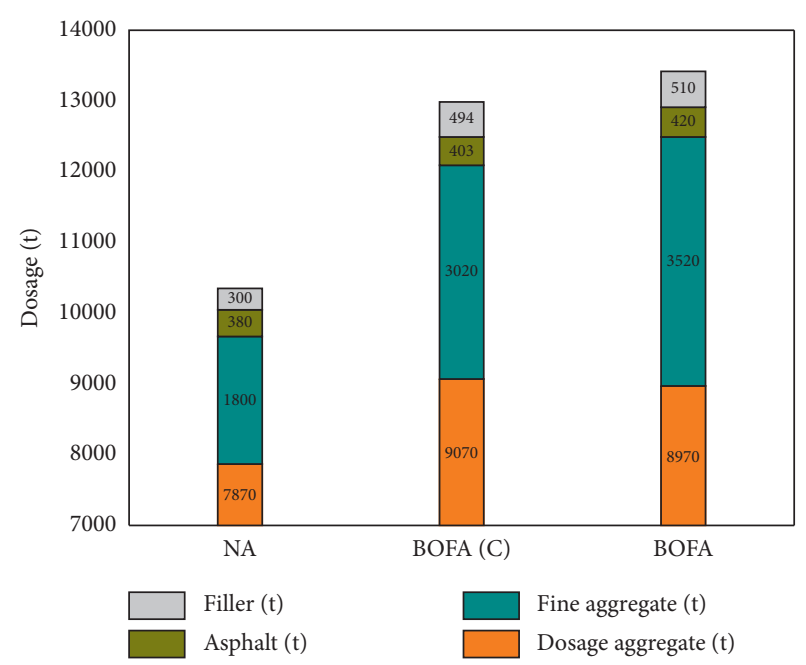

FIGURE 6: The demand for various raw materials for a $10 \mathrm{~km}$ single lane of the lower surface course.

aggregates can save a large amount of nonrenewable stone resources. Meanwhile, a great deal of steel slag is utilized resourcefully, which is beneficial to the land, water resource, and air. The application of steel slag in asphalt concrete may be its best destination. Although the amount of asphalt binder and filler will increase due to the porous nature of the steel slag, in general, the resource advantages of steel slag used as aggregate in pavement engineering are enormous. Meanwhile, the cost changes caused by steel slag as aggregate will be described in detail in the next chapter.

3.3.2. Economy Benefits Assessment. To briefly illustrate the cost advantages of steel slag over natural aggregates, a road whose length and width are $10 \mathrm{~km}$ and $3.75 \mathrm{~m}$ is used to calculate the cost. The raw materials cost decrements of all types of substitute positions and substitute modes with BOF slag were calculated and compared with ordinary asphalt mixture. The price list of the full replacement and partial replacement of natural aggregates by BOF slag is shown in Table 6 . The cost reduction rates for different substitute modes and substitute positions are shown in Figure 7. It can be derived from the analysis results that the cost decrement rates of partial replacement are $8.99 \%, 7.46 \%$, and $14.13 \%$ lower than no replacement when substitute occurs in upper, middle, and lower surface course, respectively, and the cost decrement rates of full replacement are $12.66 \%, 13.36 \%$, and $21.48 \%$ lower than no replacement when substitute occurs in upper, middle, and lower surface, course respectively. When the cost of each layer of the road is considered as a whole, partial replacement or full replacement can save $10.87 \%$ or $16.87 \%$ of the cost compared with basalt used as aggregate, respectively. It is indicated that natural aggerate is replaced by BOF slag has remarkable economic benefits. It is also found that the total replacement of natural aggregate by BOF slag is more economical than partial replacement. However, the mainstream view is that the use of more steel slag fine aggregate will lead to the increase of asphalt dosage and thus 
TABLE 5: Material savings per 10 kilometers of a one-lane road.

\begin{tabular}{lccccc}
\hline Substitute position & Substitute mode & Saving (t) & \multicolumn{2}{c}{ Disposition (t) } \\
& & Asphalt & Filler & Nature aggregate & $\begin{array}{c}\text { BOF slag } \\
\text { Upper surface course }\end{array}$ \\
& Partial & -29 & -45 & 3606 & 5214 \\
& Full & -35 & -46 & 2870 & 6716 \\
\hline \multirow{2}{*}{ Middle surface course } & Partial & -23 & -81 & 4306 & 3996 \\
& Full & -35 & -93 & 7870 & 5242 \\
\hline \multirow{2}{*}{ Lower surface course } & Partial & -23 & -194 & 9670 & 9070 \\
& Full & -40 & -210 & 12490 \\
\hline
\end{tabular}

TABle 6: Price list of asphalt mixture with BOF slag.

\begin{tabular}{|c|c|c|c|c|c|c|c|c|c|c|}
\hline \multirow{2}{*}{ Substitute position } & \multirow{2}{*}{ Substitute mode } & \multicolumn{8}{|c|}{ Materials requirements $(\mathrm{t})$ and unit price $(\mathrm{CNY} / \mathrm{t})$} & \multirow{2}{*}{$\begin{array}{c}\text { Total } \\
\text { price }(\mathrm{CNY})\end{array}$} \\
\hline & & Asphalt & Price & Filler & Price & Nature aggregate & Price & BOF slag & Price & \\
\hline \multirow{3}{*}{$\begin{array}{l}\text { Upper surface } \\
\text { course }\end{array}$} & None & 202 & \multirow{3}{*}{$\begin{array}{l}5000 \text { (modified } \\
\text { asphalt) }\end{array}$} & 135 & \multirow{3}{*}{200} & 4306 & \multirow{3}{*}{170} & 0 & \multirow{3}{*}{60} & 1769020 \\
\hline & Partial & 225 & & 216 & & 1188 & & 3996 & & 1609920 \\
\hline & Full & 237 & & 228 & & 0 & & 5242 & & 1545120 \\
\hline \multirow{3}{*}{$\begin{array}{l}\text { Middle surface } \\
\text { course }\end{array}$} & None & 242 & \multirow{3}{*}{$\begin{array}{l}5000 \text { (modified } \\
\text { asphalt) }\end{array}$} & 161 & \multirow{3}{*}{200} & 5113 & \multirow{3}{*}{170} & 0 & \multirow{3}{*}{60} & 2111410 \\
\hline & Partial & 271 & & 206 & & 1440 & & 5214 & & 1953840 \\
\hline & Full & 277 & & 207 & & 0 & & 6716 & & 1829360 \\
\hline \multirow{3}{*}{$\begin{array}{l}\text { Lower surface } \\
\text { course }\end{array}$} & None & 380 & \multirow{3}{*}{$\begin{array}{c}4000 \text { (virgin } \\
\text { asphalt) }\end{array}$} & 300 & \multirow{3}{*}{200} & 9670 & \multirow{3}{*}{170} & 0 & \multirow{3}{*}{60} & 3223900 \\
\hline & Partial & 403 & & 494 & & 3020 & & 9070 & & 2768400 \\
\hline & Full & 420 & & 510 & & 0 & & 12490 & & 2531400 \\
\hline
\end{tabular}

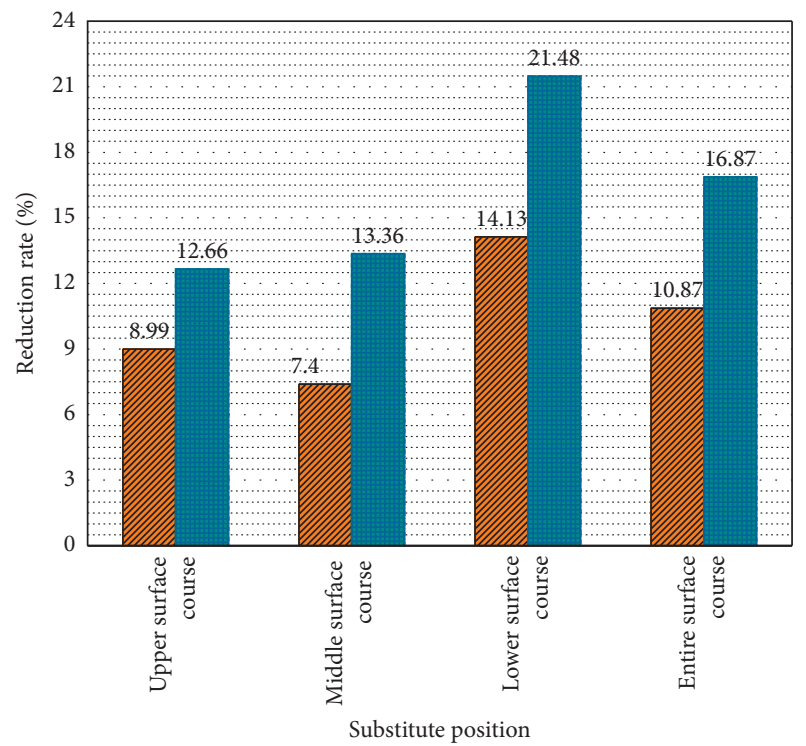

Partial replacement Full replacement

Figure 7: Cost reduction rates of BOF slag as aggregate.

increase the cost [43]. There may be two main reasons why the conclusion of this study deviates from the traditional viewpoint. (1) The calculation method in this article does not consider the transportation cost of steel slag because it is based on local materials. (2) A large amount of hydration reaction products on the surface of steel slag blocked the existing pores to a certain extent and reduced its oil absorption capacity [1].
It is worth noting that the transport distance of BOF slag used in this study is much smaller than that of natural aggregate. Consequently, transport costs are not taken into account in the assessment of the economic benefits. However, the density of steel slag is generally greater than that of natural aggregates such as basalt and limestone. Therefore, the decision should be made according to the actual situation in the application. In a study conducted by Grncel, they can tolerate the increase in transportation costs due to their excellent durability over natural aggregate. The cost and frequency of maintenance and renovation of asphalt roads will be greatly reduced by the application of steel slag [45]. In another study, Marina found that the BOF slag still shows benefits for a delivery distance up to $200 \mathrm{~km}$. However, the economic benefits of steel slag must be carefully decided when the transport distance is up to $400 \mathrm{~km}$ [44]. It is suggested that the road project manager should choose the most suitable aggregate according to the actual cost brought by the transportation distance.

\section{Conclusions}

In this research, BOF slag was investigated as an alternative aggregate in asphalt mixture to enhance sustainability. The volume stability, resource benefits, and economical assessments of steel slag were evaluated based on laboratory analysis and field application. According to the experimental results, the following conclusions can be drawn:

(1) The free calcium oxide content of the BOF slag used in this research is only $1.2958 \%$, which is far lower than the industry standard of $3 \%$. Besides, hydration treatment can effectively reduce the content of free 
calcium oxide in BOF slag, which has reference significance in practical engineering.

(2) The content of free calcium oxide in BOF slag is proportional to the particle size. However, the maximum allowable free calcium oxide content in BOF slag is inversely proportional to the particle size. This means that the expansion of steel slag with large diameter should first be paid attention to in practical applications.

(3) The optimum moisture content of steel slag aggregate used in this study is $2.0 \%$. The result of the expansion experiment of the aggregate shows that the expansion of the steel slag reaches the peak value after 6 days of immersion in water. However, the maximum expansion is only $0.661 \mathrm{~mm}$, which is far less than the maximum requirements in the specification.

(4) The expansion of steel slag asphalt concrete is less than $0.5 \%$. This may be attributed to the excellent waterproofing effect of the asphalt film on the outer layer of steel slag.

(5) The use of BOF slag in road construction can alleviate the pressure of the shortage of natural aggregate resources. Meanwhile, BOF slag may increase the demand for asphalt and filler due to its porosity and high density.

(6) The use of BOF slag to replace natural aggregates in pavement engineering has significant economic benefits. When all the aggregate of asphalt mixture is replaced by steel slag, the cost of raw materials can be reduced by $16.87 \%$. Consequently, the application of steel slag in asphalt pavement becomes a better scheme that contributes to sustainable development.

\section{Data Availability}

The data used to support the findings of this study are available from the corresponding author upon request.

\section{Conflicts of Interest}

The authors declare that they have no conflicts of interest.

\section{Authors' Contributions}

Yuechao Zhao was responsible for conceptualization, methodology, investigation, and writing of the original draft. Jiangkai Song was responsible for conceptualization, methodology, and investigation. Jun Xie and Fusong Wang were responsible for formal analysis and review and editing. Meizhu Chen was responsible for methodology and investigation. Shaopeng $\mathrm{Wu}$ was responsible for project administration, data curation, and supervision.

\section{Acknowledgments}

This work was supported by Major Science and Technology Projects of Inner Mongolia Autonomous Region (zdzx201829) and Technological Innovation Major Project of Hubei Province (2019ACA147 and 2019AE023). The authors gratefully acknowledge their financial supports.

\section{References}

[1] Z. Chen, S. Wu, Y. Xiao, W. Zeng, M. Yi, and J. Wan, "Effect of hydration and silicone resin on Basic Oxygen Furnace slag and its asphalt mixture," Journal of Cleaner Production, vol. 112, pp. 392-400, 2016.

[2] D. Zhang, M. Chen, S. Wu, Q. Liu, and J. Wan, "Preparation of expanded graphite/polyethylene glycol composite phase change material for thermoregulation of asphalt binder," Construction and Building Materials, vol. 169, pp. 513-521, 2018.

[3] H. Yang, P. Ling, Z. Yingxue, L. Quantao, and X. Jun, "The effect of water solution erosion on rheological, cohesion and adhesion properties of asphalt," Construction and Building Materials, vol. 246, Article ID 118465, 2020.

[4] N. Sakib, A. Bhasin, M. K. Islam, K. Khan, and M. I. Khan, "A review of the evolution of technologies to use sulphur as a pavement construction material," International Journal of Pavement Engineering, vol. 22, no. 3, pp. 392-403, 2019.

[5] D. Kong, S. Wu, M. Chen, M. Zhao, and B. Shu, "Characteristics of different types of basic oxygen furnace slag filler and its influence on properties of asphalt mastic," Materials, vol. 12, no. 24, Article ID 4034, 2019.

[6] S. Lv, L. Hu, C. Xia et al., "Recycling fish scale powder in improving the performance of asphalt: a sustainable utilization of fish scale waste in asphalt," Journal of Cleaner Production, vol. 288, Article ID 125682, 2021.

[7] A. Dulaimi, H. K. Shanbara, M. Sadique, and H. M. Jafer, "An evaluation of the performance of hot mix asphalt containing calcium carbide residue as a filler," Construction and Building Materials, vol. 261, Article ID 119918, 2020.

[8] J. Su, L. Peilong, S. L. Shengfei, J. B. Chenga, and Z. Dejian, "Effects of composite geometric characteristics of coarse particles on interface interactions of aggregate-asphalt system," Construction and Building Materials, vol. 287, Article ID 122750, 2021.

[9] Z. Chen, S. Wu, J. Wen, M. Zhao, M. Yi, and J. Wan, "Utilization of gneiss coarse aggregate and steel slag fine aggregate in asphalt mixture," Construction and Building Materials, vol. 93, pp. 911-918, 2015.

[10] Z. Meiling, S. Wu, Z. Chen, and C. Li, "Production and application of steel slag coarse aggregate in asphalt mixture," Emerging Materials Research, vol. 6, no. 1, pp. 219-222, 2017.

[11] A. S. Reddy, R. K. Pradhan, and S. Chandra, "Utilization of Basic Oxygen Furnace (BOF) slag in the production of a hydraulic cement binder," International Journal of Mineral Processing, vol. 79, no. 2, pp. 98-105, 2006.

[12] F. Han, Z. Zhang, D. Wang, and P. Yan, "Hydration heat evolution and kinetics of blended cement containing steel slag at different temperatures," Thermochimica Acta, vol. 605, pp. 43-51, 2015.

[13] D.-H. Shen, C.-M. Wu, and J.-C. Du, "Laboratory investigation of basic oxygen furnace slag for substitution of aggregate in porous asphalt mixture," Construction and Building Materials, vol. 23, no. 1, pp. 453-461, 2009.

[14] M. R. Hainin, M. A. Aziz, Z. Ali, and R. P. Jaya, "Steel slag as A road construction," Material. Jurnal Teknologi, vol. 73, no. 4, 2015.

[15] R. Hu, J. Xie, S. Wu, C. Yang, and D. Yang, "Study of toxicity assessment of heavy metals from steel slag and its asphalt mixture," Materials, vol. 13, no. 12, 2020. 
[16] T. Lee, S. Jung, Y. K. Park et al., "Catalytic pyrolysis of polystyrene over steel slag under CO2 environment," Journal of Hazardous Materials, vol. 395, Article ID 122576, 2020.

[17] T. Wen, Y. Liyun, D. Chenyuan, M. Takahiro, B. Hao, and N. Tetsuya, "Effect of basic oxygen furnace slag on succession of the bacterial community and immobilization of various metal ions in acidic contaminated mine soil," Journal of Hazardous Materials, vol. 388, Article ID 121784, 2020.

[18] E. A. Oluwasola and M. R. Hainin, "Evaluation of performance characteristics of stone mastic asphalt incorporating industrial waste," Journal of Materials in Civil Engineering, vol. 28, no. 12, 2016.

[19] V. Antunes, A. C. Freire, L. Quaresma, and R. Micaelo, "Effect of the chemical composition of fillers in the filler-bitumen interaction," Construction and Building Materials, vol. 104, pp. 85-91, 2016.

[20] P. Cui, S. Wu, Y. Xiao, Q. Liu, and F. Wang, "Hazardous characteristics and variation in internal structure by hydrodynamic damage of BOF slag-based thin asphalt overlay," Journal of Hazardous Materials, vol. 412, Article ID 125344, 2021.

[21] J. Xie, Z. Wang, F. Wang, S. Wu, Z. Chen, and C. Yang, "The life cycle energy consumption and emissions of asphalt pavement incorporating basic oxygen furnace slag by comparative study," Sustainability, vol. 13, no. 8, 2021.

[22] P. Ahmedzade and B. Sengoz, "Evaluation of steel slag coarse aggregate in hot mix asphalt concrete," Journal of Hazardous Materials, vol. 165, no. 1-3, pp. 300-305, 2009.

[23] Y. Huang, R. N. Bird, and O. Heidrich, "A review of the use of recycled solid waste materials in asphalt pavements," $R e$ sources, Conservation and Recycling, vol. 52, no. 1, pp. 58-73, 2007.

[24] Y. Xue, S. Wu, H. Hou, and J. Zha, "Experimental investigation of basic oxygen furnace slag used as aggregate in asphalt mixture," Journal of Hazardous Materials, vol. 138, no. 2, pp. 261-268, 2006.

[25] M. Pasetto and N. Baldo, "Experimental evaluation of high performance base course and road base asphalt concrete with electric arc furnace steel slags," Journal of Hazardous Materials, vol. 181, no. 1-3, pp. 938-948, 2010.

[26] M. Pasetto and N. Baldo, "Fatigue behavior characterization of bituminous mixtures made with reclaimed asphalt pavement and steel slag," Procedia-Social and Behavioral Sciences, vol. 53, pp. 297-306, 2012.

[27] E. Masad, D. Little, and R. Sukhwani, "Sensitivity of HMA performance to aggregate shape measured using conventional and image analysis methods," Road Materials and Pavement Design, vol. 5, no. 4, pp. 477-498, 2011.

[28] G. Tao, Y. Xiao, L. Yang, P. Cui, D. Kong, and Y. Xue, "Characteristics of steel slag filler and its influence on rheological properties of asphalt mortar," Construction and Building Materials, vol. 201, pp. 439-446, 2019.

[29] C. Li, Z. Chen, S. Wu, B. Li, J. Xie, and Y. Xiao, "Effects of steel slag fillers on the rheological properties of asphalt mastic," Construction and Building Materials, vol. 145, pp. 383-391, 2017.

[30] I. Liapis and I. Papayianni, "Advances in chemical and physical properties of electric arc furnace carbon steel slag by hot stage processing and mineral mixing," Journal of Hazardous Materials, vol. 283, pp. 89-97, 2015.

[31] J. Wan, S. Wu, Y. Xiao, Z. Chen, and D. Zhang, "Study on the effective composition of steel slag for asphalt mixture induction heating purpose," Construction and Building Materials, vol. 178, pp. 542-550, 2018.
[32] J. Baalamurugan, V. Ganesh Kumar, S. Chandrasekaran et al., "Utilization of induction furnace steel slag in concrete as coarse aggregate for gamma radiation shielding," Journal of Hazardous Materials, vol. 369, pp. 561-568, 2019.

[33] P. Cui, S Wu, Y Xiao, R Hu, and T Yang, "Environmental performance and functional analysis of chip seals with recycled basic oxygen furnace slag as aggregate," Journal of Hazardous Materials, vol. 405, Article ID 124441, 2020.

[34] S. Pathak, R. Choudhary, A. Kumar, and S. K. Shukla, "Evaluation of benefits of open-graded friction courses with basic oxygen furnace steel-slag aggregates for hilly and highrainfall regions in India," Journal of Materials in Civil Engineering, vol. 32, no. 12, 2020.

[35] G. Wang, Y. Wang, and Z. Gao, "Use of steel slag as a granular material: volume expansion prediction and usability criteria," Journal of Hazardous Materials, vol. 184, no. 1-3, pp. 555-560, 2010.

[36] V. A. Nunes and P. H. R. Borges, "Recent advances in the reuse of steel slags and future perspectives as binder and aggregate for alkali-activated materials," Construction and Building Materials, vol. 281, Article ID 122605, 2021.

[37] B. Peng, D. Y. Wu, S. C. Yue, and Y. X. Li, "Achieving stable steelmaking basic oxygen furnace slag through treatment by self-disintegration high pressure process," Metallurgical Research \& Technology, vol. 118, no. 2, 2021.

[38] L. M. Juckes, "The volume stability of modern steelmaking slags," Transactions of the Institution Of Mining And Metallurgy Section C-Mineral Processing And Extractive Metallurgy, vol. 112, no. 3, pp. C177-C197, 2003.

[39] H. Wei, J. Li, F. Wang, J. Zheng, Y. Tao, and Y. Zhang, "Numerical investigation on fracture evolution of asphalt mixture compared with acoustic emission," International Journal of Pavement Engineering, vol. 13, pp. 1-11, 2021.

[40] C. Shi, "Steel slag-its production, processing, characteristics, and c properties," Journal of Materials in Civil Engineering, vol. 16, no. 3, pp. 230-236, 2004.

[41] L. Yunpeng, P. Ling, and Z. Yingxue, "Study on volume stability of hot stuff and hot splash steel slag sand," Journal of Wuhan University of Technology, vol. 44, no. 6, 2020.

[42] L. Zhang and Z. Lu, "Comparative analysis of evaluation methods for steel slag soundness," Environmental Engineering, vol. 12, no. 21, pp. 1-7, 2021.

[43] L. He, C. Zhan, S. Lv et al., "Application status of steel slag asphalt mixture," Journal of Traffic and Transportation Engineering, vol. 20, no. 2, pp. 15-33, 2020.

[44] M. Diaz-Piloneta, M. Terrados-Cristos, J. V. Alvarez-Cabal, and E. Vergara-Gonzalez, "Comprehensive analysis of steel slag as aggregate for road construction: experimental testing and environmental impact assessment," Materials (Basel), vol. 14 , no. 13 , p. $3587,2021$.

[45] O. Gencel, K. Omer, H. O. Osman, and B. Turhan, "Steel slag and its applications in cement and concrete technology: a review," Construction and Building Materials, vol. 283, Article ID 122783, 2021. 